Article

\title{
A Simple and Sensitive Liquid Chromatography with Tandem Mass Spectrometric Method for the Simultaneous Determination of Anthraquinone Glycosides and Their Aglycones in Rat Plasma: Application to a Pharmacokinetic Study of Rumex acetosa Extract
}

\author{
Hossain Mohammad Arif Ullah ${ }^{+}{ }^{(D)}$, Junhyeong Kim ${ }^{\dagger}$, Naveed Ur Rehman, Hye-Jin Kim, \\ Mi-Jeong Ahn * and Hye Jin Chung * (iD \\ College of Pharmacy and Research Institute of Pharmaceutical Sciences, Gyeongsang National University, \\ Jinju 52828, Korea; arifpha@ymail.com (H.M.A.U.); jhk6914@naver.com (J.K.); \\ naveed.rehman50@gmail.com (N.U.R.); black200203@gmail.com (H.-J.K.) \\ * Correspondence: amj5812@gnu.ac.kr (M.-J.A.); hchung@gnu.ac.kr (H.J.C.); \\ Tel.: +82-55-772-2425 (M.-J.A.); +82-55-772-2430 (H.J.C.) \\ + These authors contributed equally to this work.
}

Received: 24 June 2018; Accepted: 18 July 2018; Published: 20 July 2018

\begin{abstract}
Rumex acetosa (R. acetosa) has been used in folk remedies for gastrointestinal disorders and cutaneous diseases. Rumex species, in particular, contain abundant anthraquinones. Anthraquinone glycosides and aglycones show different bioactive effects. However, information on the pharmacokinetics of anthraquinone glycosides is limited, and methods to quantify anthraquinone glycosides in plasma are rarely available. A simple and sensitive liquid chromatography-tandem mass spectrometric bioanalytical method for the simultaneous determination of both anthraquinone glycosides and their aglycones, including emodin, emodin- $8-O-\beta$-D-glucoside, chrysophanol, chrysophanol-8-O- $\beta$-D-glucoside, physcion, and physcion- $8-O-\beta$-D-glucoside , in a low volume of rat plasma $(20 \mu \mathrm{L})$ was established. A simple and rapid sample preparation was employed using methanol as a precipitating agent with appropriate sensitivity. Chromatographic separation was performed on HPLC by using a biphenyl column with a gradient elution using $2 \mathrm{mM}$ ammonium formate $(\mathrm{pH} 6)$ in water and $2 \mathrm{mM}$ ammonium formate $(\mathrm{pH} \mathrm{6)}$ in methanol within a run time of $13 \mathrm{~min}$. The anthraquinones were detected on triple-quadrupole mass spectrometer in negative ionization mode using multiple-reaction monitoring. The method was validated in terms of selectivity, linearity, accuracy, precision, recovery, and stability. The values of the lower limit of quantitation of anthraquinones were 1-20 ng/mL. The intra-batch and inter-batch accuracies were $96.7-111.9 \%$ and the precision was within the acceptable limits. The method was applied to a pharmacokinetic study after oral administration of $R$. acetosa $70 \%$ ethanol extract to rats at a dose of $2 \mathrm{~g} / \mathrm{kg}$.
\end{abstract}

Keywords: anthraquinone; glycoside; aglycone; LC-MS/MS; plasma; protein precipitation

\section{Introduction}

Rumex acetosa L. (R. acetosa), belonging to the Polygonaceae family, is a perennial herb that is listed in the Korean Food Code (Korea Food and Drug Administration) as a food material and has been used in folk remedies for gastrointestinal disorders and cutaneous diseases [1]. Extracts of $R$. acetosa have been reported to have various biological activities, including anti-ulcerogenic, 
anti-inflammatory, anti-proliferative, and anti-viral effects [2-4]. They contain a number of bioactive compounds, including anthraquinones, flavonoids, and polysaccharides [5]. In particular, Rumex species contain abundant anthraquinones, including emodin, chrysophanol, and physcion in all parts of the plant, in free and glycoside forms [6]. A difference in anthraquinone physiological activity between these forms has been described [7]. Previous studies reported a number of quantitative methods of anthraquinones in plasma [8-10]. However, we found that most of these studies focused on determining aglycones (free anthraquinones). Methods to quantify anthraquinone glycosides in plasma are rarely available.

As interest in natural drugs has increased in the pharmaceutical industry, research is underway to develop potential applications of $R$. acetosa, which has already proven its efficacy. Therefore, a simple and sensitive analytical method to examine bioactive anthraquinones in biological samples is needed to evaluate the potential of new treatments.

The aim of this study is to establish a simple, rapid, and sensitive liquid chromatography-tandem mass spectrometry (LC-MS/MS) method to simultaneously quantify emodin (E), emodin-8-O$\beta$-D-glucoside (EG), chrysophanol (C), chrysophanol-8-O- $\beta$-D-glucoside (CG), physcion (P), and physcion-8-O- $\beta$-D-glucoside (PG) in rat plasma within one chromatographic run. The method was applied to determine pharmacokinetic parameters after oral administration of $R$. acetosa $70 \%$ ethanol extract in rat. The results of this study might be helpful in the development of a new type of medicine using R. acetosa.

\section{Materials and Methods}

\subsection{Materials}

The plant of R. acetosa L. (Polygonaceae) was collected from the Sancheong province of Korea in April 2014 and identified by Mi-Jeong Ahn of the College of Pharmacy, Gyeongsang National University (Jinju, Korea). The voucher specimen (APG-1403) was deposited in the Herbarium of the College of Pharmacy, Gyeongsang National University. The standards of the six anthraquinones (E, EG, C, CG, P, and PG) were isolated from the whole part of R. acetosa and their structures (Figure 1) were elucidated using spectroscopy such as MS and nuclear magnetic resonance spectroscopy (data not shown) [11]. The purity of anthraquinone compounds isolated from $R$. acetosa was confirmed to be more than $95 \%$ by NMR and HPLC-UV. Diclofenac used as an internal standard (IS) was purchased from Sigma Aldrich (St. Louis, MO, USA). HPLC-grade acetonitrile, methanol, and water were products of Fisher Scientific Korea Ltd. (Seoul, Korea). All reagents were analytical grade.
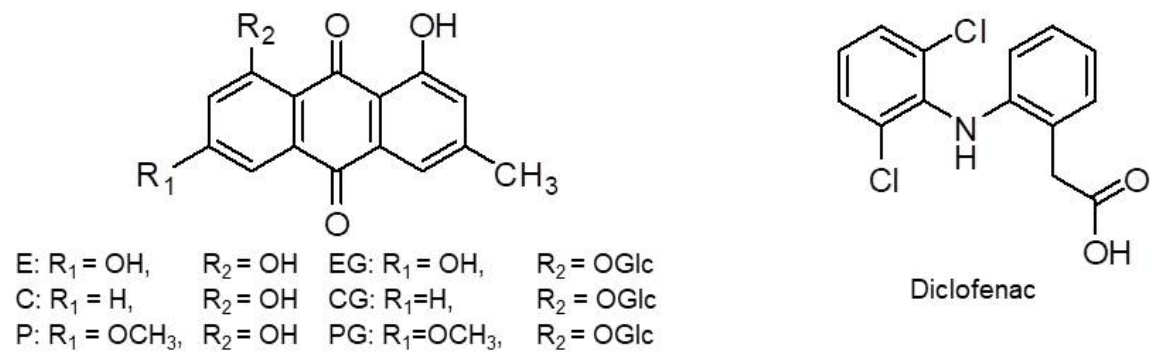

Figure 1. The chemical structures of six anthraquinones and diclofenac (internal standard). E, emodin; EG, emodin-8-O- $\beta$-D-glucoside; $C$, chrysophanol; CG, chrysophanol-8-O- $\beta$-D-glucoside; $\mathrm{P}$, physcion; PG, physcion-8-O- $\beta$-D-glucoside.

\subsection{Chromatographic Condition}

The analysis was performed on an Agilent 1260 series (Agilent Technologies, Waldbronn, Germany) HPLC system. Chromatographic separation of the samples was carried out on a Kinetex Biphenyl column $(100 \times 3.0$ mm, $2.6 \mu \mathrm{m}, 110 \AA$ A, Phenomenex, Torrance, CA, USA). The mobile phase 
consisted of $2 \mathrm{mM}$ ammonium formate ( $\mathrm{pH}$ 6) in water (A) and $2 \mathrm{mM}$ ammonium formate (pH 6) in methanol (B). The gradient program was used at a flow rate of $0.3 \mathrm{~mL} / \mathrm{min}$ while maintaining the column temperature at $40{ }^{\circ} \mathrm{C}$. The mobile phase initial composition of $25 \% \mathrm{~B}$ was maintained for $2 \mathrm{~min}$. It was then increased linearly from $25 \%$ to $95 \%$ B for $0.5 \mathrm{~min}$ and held for $7 \mathrm{~min}$. The gradient was then changed back to the initial condition for $0.5 \mathrm{~min}$ and kept at the initial condition for $3 \mathrm{~min}$. The total analysis time was $13 \mathrm{~min}$ for each sample. The injection volume was $15 \mu \mathrm{L}$.

\subsection{Mass Spectrometric Condition}

The mass spectrometric detection was performed on an Agilent 6460 triple-quadruple mass spectrometer (Agilent Technologies, Singapore) with an electrospray ionization source. It was operated in the negative ion detection mode because of its higher sensitivity than that in the positive ionization mode on multiple reaction monitoring (MRM). The data were acquired and processed using Mass Hunter Workstation B.06.00 software (Agilent Technologies, Singapore). The mass spectrometric parameters of each compound are summarized in Table 1 [12]. The MS spectra of the six anthraquinones are shown in Figure 2. The source parameters were also optimized as follows: a drying gas flow and temperature at $6 \mathrm{~L} / \mathrm{min}$ and $350{ }^{\circ} \mathrm{C}$ were used, respectively; the sheath gas flow and temperature were maintained at $12 \mathrm{~L} / \mathrm{min}$ and $350{ }^{\circ} \mathrm{C}$, respectively; the nebulizing gas $\left(\mathrm{N}_{2}\right)$ pressure was set at 25 psi; and the capillary and nozzle voltages were set at $3500 \mathrm{~V}$ and $500 \mathrm{~V}$, respectively.

(A)

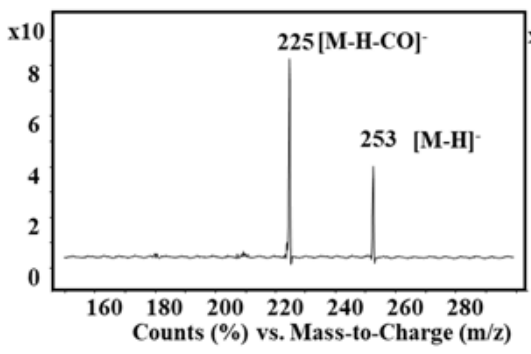

(C)

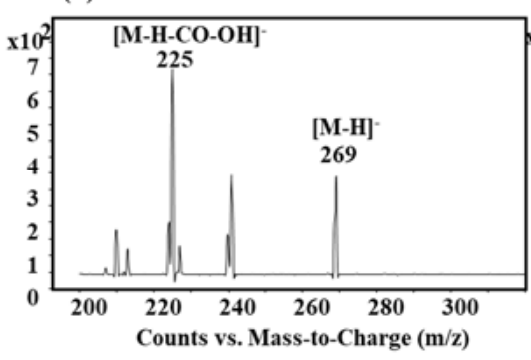

(E)
(B)

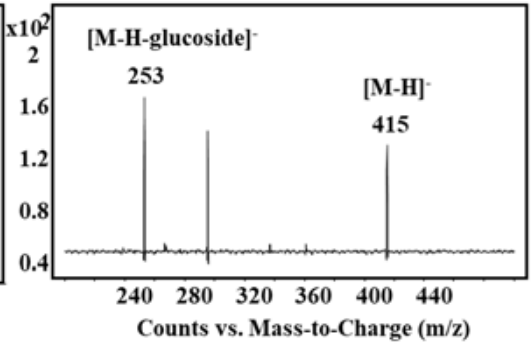

(D)

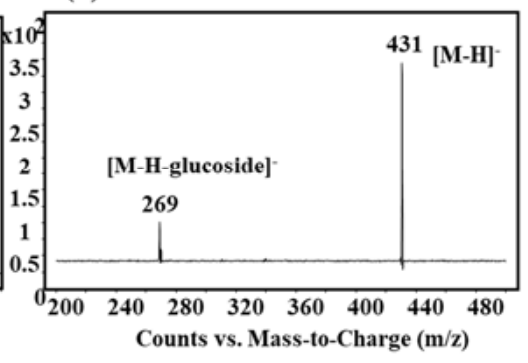

(F)

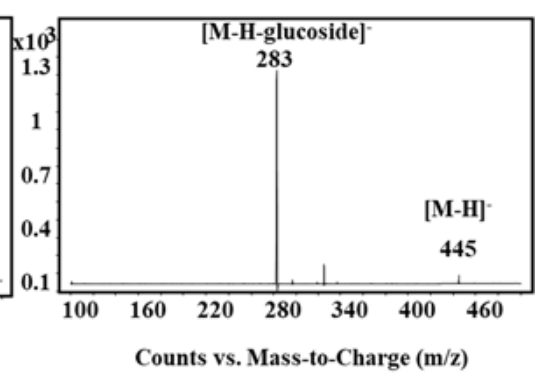

Figure 2. MS/MS scan spectra of six anthraquinones. (A) chrysophanol; (B) chrysophanol-8-O$\beta$-D-glucoside; (C) emodin; (D) emodin-8-O- $\beta$-D-glucoside; (E) physcion; (F) physcion-8-O$\beta$-D-glucoside. 
Table 1. Summary of the MS/MS parameters.

\begin{tabular}{|c|c|c|c|}
\hline Compounds & $\begin{array}{c}\text { MRM Transition }(\mathrm{m} / \mathrm{z})^{\mathrm{a}} \\
\text { Precursor Ion } \rightarrow \text { Product Ion }\end{array}$ & Fragmentor (V) & Collision Energy (V) \\
\hline $\mathrm{E}$ & $269 \rightarrow 225$ & 145 & 20 \\
\hline EG & $431 \rightarrow 269$ & 150 & 24 \\
\hline $\mathrm{C}$ & $253 \rightarrow 225$ & 175 & 22 \\
\hline CG & $415 \rightarrow 253$ & 89 & 13 \\
\hline $\mathrm{P}$ & $283 \rightarrow 240$ & 157 & 16 \\
\hline PG & $445 \rightarrow 283$ & 95 & 5 \\
\hline IS (Diclofenac) & $294 \rightarrow 250$ & 65 & 1 \\
\hline
\end{tabular}

\subsection{Preparation of R. acetosa Extract}

The dried plant material (100 g) was ground and extracted with 70\% ethanol. The extract was filtered using filter papers (Whatman No. 40) and concentrated through a rotary evaporator. The concentrate was lyophilized and stored at $-80{ }^{\circ} \mathrm{C}$. The exact amount was weighed and used as the samples for the animal studies. The contents of E, EG, C, CG, P, and PG in R. acetosa extract were $0.94 \pm 0.15 \%, 1.29 \pm 0.06 \%, 0.68 \pm 0.09 \%, 0.77 \pm 0.12 \%, 0.17 \pm 0.02 \%$, and $0.41 \pm 0.05 \%(w / w)$, respectively. The values were expressed as mean \pm standard deviation.

\subsection{Preparation of the Calibration Standard and Quality Control (QC) Samples}

The primary stock solutions of E, EG, C, CG, P, PG, and IS were prepared in dimethyl sulfoxide at a concentration of $1 \mathrm{mg} / \mathrm{mL}$ and stored at $-80{ }^{\circ} \mathrm{C}$. The mixture stock solutions to obtain the standard solutions were serially diluted in methanol. The IS stock solution of $5 \mathrm{ng} / \mathrm{mL}$ was prepared in methanol. The calibration standards were prepared by spiking $10 \mu \mathrm{L}$ of above standard solutions into $90 \mu \mathrm{L}$ of blank rat plasma to yield concentration ranges of $1-300 \mathrm{ng} / \mathrm{mL}$ for $\mathrm{E}, 20-300 \mathrm{ng} / \mathrm{mL}$ for $\mathrm{P}$ and $\mathrm{C}, 1-150 \mathrm{ng} / \mathrm{mL}$ for EG, $10-150 \mathrm{ng} / \mathrm{mL}$ for CG and PG. Twenty microliters of aliquots were prepared and stored at $-80^{\circ} \mathrm{C}$ until analysis.

The QC samples were prepared in the same way as the calibration samples for E, EG, C, CG, P, and PG in rat plasma at low, middle, and high concentrations. All the solutions were kept at $-80{ }^{\circ} \mathrm{C}$.

\subsection{Sample Preparation}

To $20 \mu \mathrm{L}$ aliquot of the rat plasma samples, $60 \mu \mathrm{L}$ of $5 \mathrm{ng} / \mathrm{mL}$ IS in methanol was added. The mixture was vortexed for $30 \mathrm{~s}$ and kept at $4{ }^{\circ} \mathrm{C}$ for $30 \mathrm{~min}$. The mixture was centrifuged at $10,000 \times g$ for $10 \mathrm{~min}$. The supernatant was transferred to an HPLC vial, and $15 \mu \mathrm{L}$ of the processed sample was injected onto the LC-MS/MS system.

\subsection{Method Validation}

The method validation was performed according to the United States Food and Drug Administration's guidance on bioanalytical method validation [13].

\subsubsection{Selectivity}

The selectivity study was performed by comparing the chromatograms of the six different rat plasma samples to investigate the interference near the retention time of the analytes and the IS.

\subsubsection{Calibration Curves and Sensitivity}

The linearity of each calibration curve was determined by plotting the peak area ratio of the analyte to IS versus the plasma concentrations. The least-square method was used to achieve a linear 
regression equation. Sensitivity was defined by calculating the lower limit of detection and the lower limit of quantification (LLOQ) based on a signal-to-noise ratio of greater than 3 and 10, respectively. Besides signal-to-noise ratio, LLOQ values with acceptable precision and accuracy values were chosen. The criteria of precision and accuracy at LLOQ are within 20\% relative standard deviation (RSD) for precision and between $80-120 \%$ for accuracy.

\subsubsection{Precision and Accuracy}

Precision and accuracy were investigated by analyzing six replicates of four QC levels on the same batch (intra-batch) and five different batches (inter-batch) of four QC levels (LLOQ, low QC, middle QC, and high QC). The intra- and inter-batch precision was expressed by RSD (\%), and accuracy was evaluated by expressing it as a percentage of the theoretical value (the mean calculated concentration/nominal concentration) $\times 100 \%$. The acceptance criteria are within $15 \%$ RSD except $20 \%$ at LLOQ for precision and $\pm 15 \%$ of nominal concentrations except $\pm 20 \%$ at LLOQ for accuracy.

\subsubsection{Extraction Recovery and Matrix Effect}

The extraction recovery was evaluated by comparing the peak area of the extracted sample with that of the post-extracted sample at three replicates of three QC levels. The matrix effect of the analytes was investigated by comparing the peak area of the post-extracted sample with the peak area obtained by the corresponding standard solutions in $\mathrm{pH} 7.4$ buffer at three QC levels. Matrix effects were determined using the equation below.

$$
\left(\frac{\text { peak area of the analytes for the sample spiked with the target compounds after extraction }}{\text { peak area of the analytes for the standard solutions }}\right) \times 100 \%
$$

\subsubsection{Stability}

The stability of the analytes in rat plasma was evaluated by analyzing triplicates of three QC levels at room temperature for $4 \mathrm{~h}$ (short-term stability), $-80^{\circ} \mathrm{C}$ for one month (long-term stability), three freeze-thaw cycles from $-80^{\circ} \mathrm{C}$ to room temperature (freeze and thaw stability), and $4{ }^{\circ} \mathrm{C}$ for $24 \mathrm{~h}$ (processed sample stability). The stability of analytes in stock solution was also evaluated. The peak areas obtained from freshly prepared stock solutions were compared with stock solutions stored for $4 \mathrm{~h}$ at room temperature.

\subsection{Pharmacokinetic Study}

Male Sprague-Dawley rats (8-week-old, weighing $250 \pm 10$ g) were obtained from Koatech (Pyeongtaek, Korea). They were housed and acclimated in the Animal Laboratory, Gyeongsang National University, under controlled temperature and humidity and regular $12 \mathrm{~h}$ light cycle, freely accessible to food and water for 7 days before the experiment. The rats were cannulated into the carotid artery and allowed to recover for one day. Before the pharmacokinetic study, all rats were fasted for $12 \mathrm{~h}$ with free access to water. $R$. acetosa extract suspended in a solution (ethanol:polysorbate 80:water =1:2:7, $v / v / v$ ) was orally administered to the three rats at a dose of $2 \mathrm{~g} / \mathrm{kg}$. The calculated doses of compounds based on the contents in the extract were 18.8, 25.8, 13.6, 15.4, 3.4, and $8.2 \mathrm{mg} / \mathrm{kg}$ for E, EG, C, CG, P, and PG, respectively. Blood samples $(100 \mu \mathrm{L})$ were collected via the cannulated carotid vessel at 0,15 , $30,45 \mathrm{~min}, 1,2,3,4,6,8,12$, and $24 \mathrm{~h}$ after oral administration. To collect plasma, the blood samples were immediately centrifuged at $10,000 \times g$ for $5 \mathrm{~min}$. All plasma samples were stored at $-80{ }^{\circ} \mathrm{C}$ until analysis. All experimental procedures of the animal study were approved (GNU-130618-R0038) by the Animal Care and Use Committee of Gyeongsang National University, Korea. 


\section{Results}

\subsection{Method Validation}

\subsubsection{Specificity and Selectivity}

The representative MRM chromatograms of blank rat plasma and that spiked with six anthraquinones and IS are shown in Figure 3. No interference from endogenous substances near the retention time of the analytes or the IS was observed.

(A)

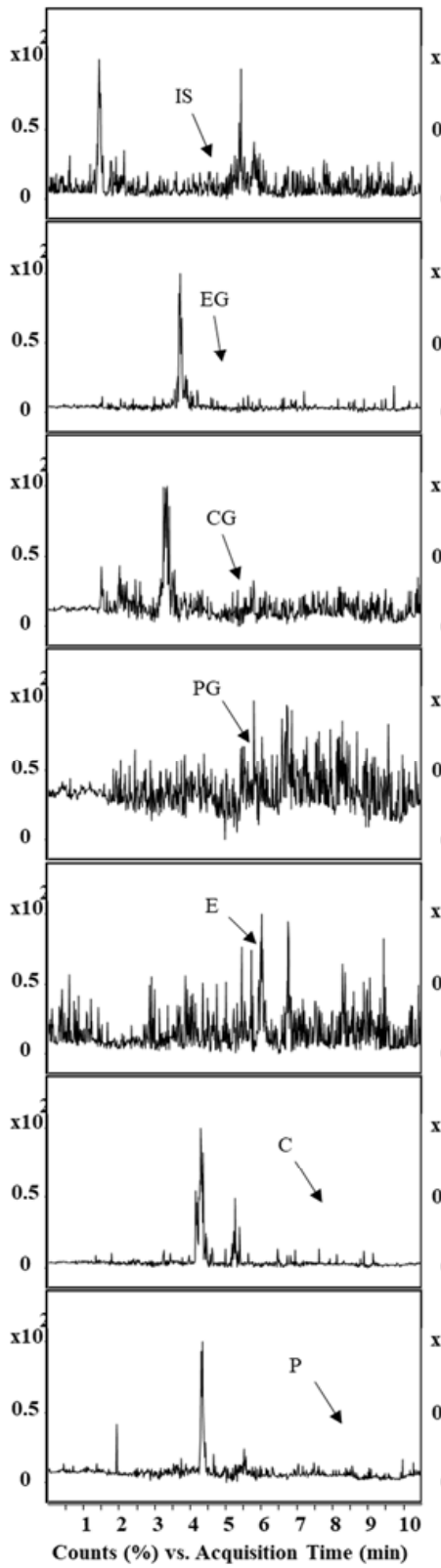

(B)

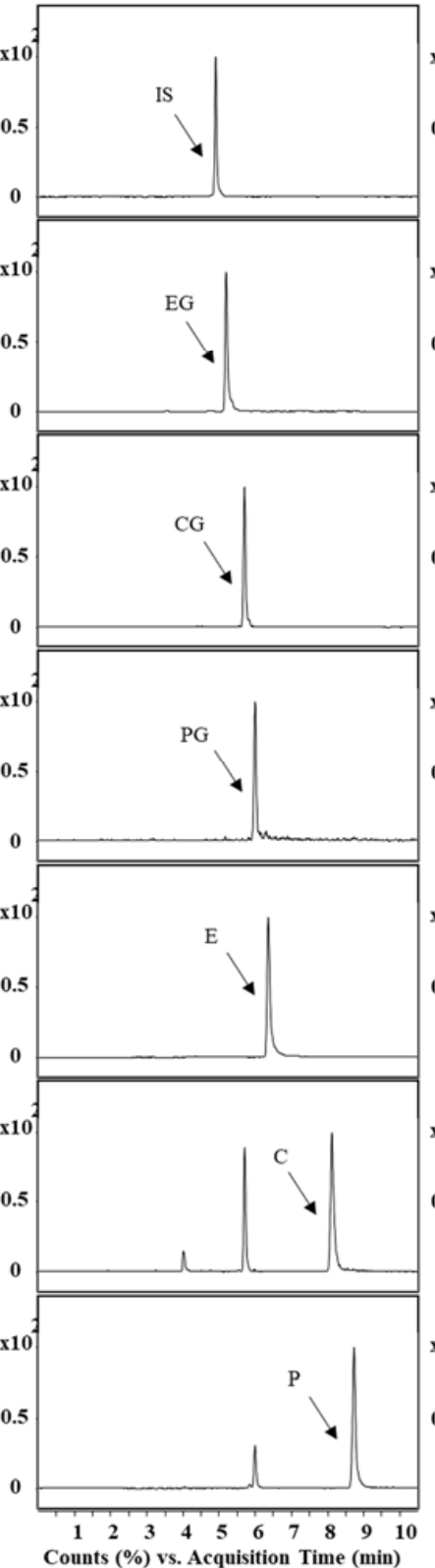

(C)

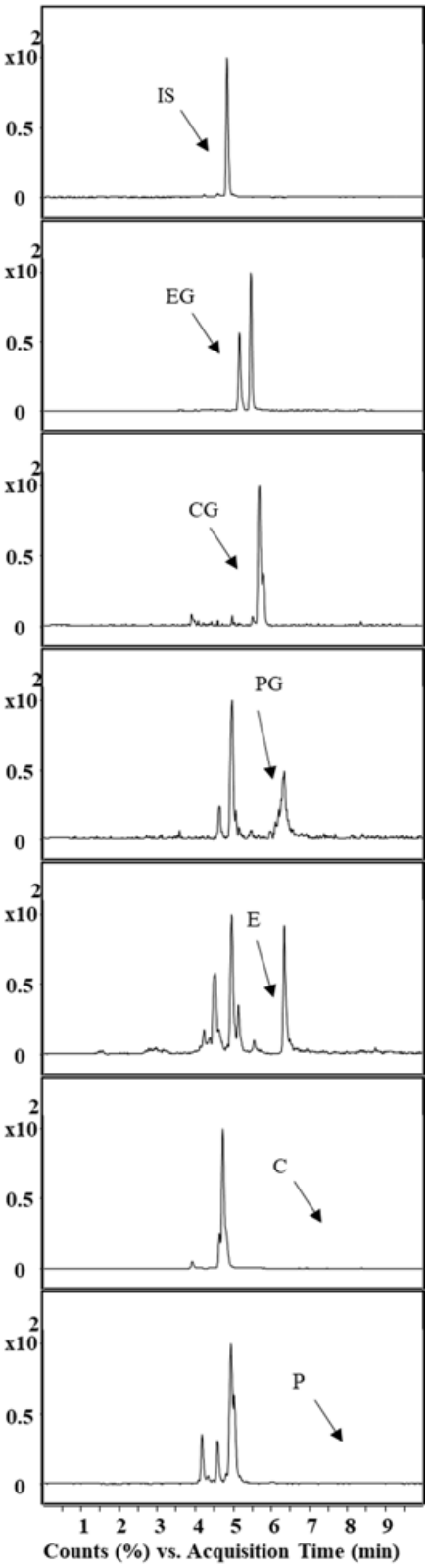

Figure 3. Representative MRM chromatograms of IS, EG, CG, PG, E, C, and P in rat plasma. (A) blank plasma; (B) blank plasma spiked with six anthraquinones $(250 \mathrm{ng} / \mathrm{mL}$ for aglycones and $125 \mathrm{ng} / \mathrm{mL}$ for glycosides) and IS; (C) plasma sample obtained from rats $45 \mathrm{~min}$ after oral administration of $R$. acetosa extract $(2 \mathrm{~g} / \mathrm{kg})$. 


\subsubsection{Linearity and Sensitivity}

The calibration curves showed good linearity over their corresponding ranges for the analytes $\left(R^{2}>0.9934\right)$.

\subsubsection{Precision and Accuracy}

The intra- and inter-batch precision and accuracies are presented in Table 2. The RSD values for the intra- and inter-batch were below 13.5\%, except for EG at LLOQ (18.9\%). The accuracies were between $85 \%$ and $115 \%$. All results showed acceptable accuracy and precision.

Table 2. Accuracy and precision of anthraquinones in rat plasma $(n=6)$. RSD: relative standard deviation.

\begin{tabular}{|c|c|c|c|c|c|c|c|}
\hline Analyte & $\begin{array}{c}\text { Nominal } \\
\text { Concentration } \\
(\mathrm{ng} / \mathrm{mL})\end{array}$ & \multicolumn{3}{|c|}{ Intra-Batch } & \multicolumn{3}{|c|}{ Inter-Batch } \\
\hline \multirow{3}{*}{$\mathrm{P}$} & 20 & 20.5 & 102.5 & 8.83 & 21.3 & 106.4 & 11.2 \\
\hline & 60 & 58.0 & 96.7 & 4.69 & 63.4 & 105.6 & 7.72 \\
\hline & 150 & 156 & 104.2 & 3.98 & 158 & 105.3 & 5.90 \\
\hline \multirow{4}{*}{$\mathrm{E}$} & 1 & 1.10 & 110.1 & 13.5 & 1.05 & 104.6 & 11.1 \\
\hline & 3 & 3.31 & 110.3 & 6.87 & 3.12 & 103.9 & 6.87 \\
\hline & 150 & 155 & 103.4 & 2.32 & 154 & 102.8 & 2.66 \\
\hline & 300 & 309 & 103.0 & 3.45 & 299 & 99.8 & 2.28 \\
\hline $\mathrm{C}$ & 20 & 21.8 & 109.2 & 9.23 & 19.8 & 98.9 & 2.98 \\
\hline \multirow{4}{*}{ PG } & 10 & 10.2 & 102.1 & 10.7 & 10.2 & 102.3 & 12.1 \\
\hline & 30 & 32.1 & 107.1 & 6.83 & 31.7 & 105.7 & 5.72 \\
\hline & 75 & 80.3 & 107.1 & 5.38 & 80.5 & 107.3 & 4.95 \\
\hline & 150 & 160 & 106.5 & 4.13 & 159 & 106.2 & 4.89 \\
\hline \multirow{4}{*}{ EG } & 1 & 1.10 & 110.1 & 18.9 & 1.05 & 105.2 & 9.10 \\
\hline & 3 & 3.35 & 111.8 & 5.49 & 3.27 & 108.9 & 12.9 \\
\hline & 75 & 77.3 & 103.0 & 1.59 & 78.5 & 104.6 & 3.85 \\
\hline & 150 & 156 & 104.1 & 1.24 & 153.9 & 102.6 & 4.34 \\
\hline \multirow{3}{*}{ CG } & 10 & 11.2 & 111.9 & 8.34 & 11.0 & 109.9 & 8.00 \\
\hline & 30 & 31.5 & 105.0 & 4.13 & 31.6 & 105.4 & 5.79 \\
\hline & 75 & 76.3 & 101.7 & 2.72 & 76.5 & 102.0 & 3.16 \\
\hline
\end{tabular}

\subsubsection{Extraction Recovery and Matrix Effect}

The extraction recoveries and matrix effects of the anthraquinone compounds are shown in Table 3. The matrix effects were consistent among different concentrations for each compound. The recoveries ranged from $96.0 \%$ to $112.7 \%$ for the analytes at the QC levels. The matrix effects were constant for each analyte with different concentrations.

\subsubsection{Stability}

The stability of stock solution was determined. As compared with fresh stock solutions, the mean concentration of analytes $(n=3)$ in stock solutions stored at room temperature for $4 \mathrm{~h}$ were 99.2, 94.8, 95.9, 102.4, 100.4, and 101.7\% for P, E, C, PG, EG, and CG, respectively. There was no detectable degradation of compounds in dimethyl sulfoxide and methanol stored at room temperature for 3 months based on HPLC-UV chromatogram. The stability results of the analytes in rat plasma under different conditions are shown in Table 4. 
Table 3. Extraction recovery and matrix effect of anthraquinones in rat plasma $(n=3)$.

\begin{tabular}{|c|c|c|c|c|c|}
\hline \multirow{2}{*}{ Analyte } & \multirow{2}{*}{ Nominal Concentration (ng/mL) } & \multicolumn{2}{|c|}{ Extraction Recovery (\%) } & \multicolumn{2}{|c|}{ Matrix Effect (\%) } \\
\hline & & Mean & RSD & Mean & RSD \\
\hline \multirow{3}{*}{$\mathrm{P}$} & 60 & 106.5 & 4.85 & 185.6 & 2.29 \\
\hline & 150 & 106.4 & 1.23 & 185.1 & 3.13 \\
\hline & 300 & 98.6 & 1.49 & 183.9 & 3.92 \\
\hline \multirow{3}{*}{$\mathrm{E}$} & 3 & 101.3 & 2.74 & 70.1 & 6.65 \\
\hline & 150 & 105.6 & 0.82 & 87.0 & 1.46 \\
\hline & 300 & 100.4 & 1.90 & 92.3 & 2.77 \\
\hline \multirow{3}{*}{$\mathrm{C}$} & 60 & 112.7 & 8.71 & 143.0 & 1.04 \\
\hline & 150 & 102.1 & 1.07 & 144.3 & 1.62 \\
\hline & 300 & 96.6 & 1.04 & 144.6 & 4.11 \\
\hline \multirow{3}{*}{ PG } & 30 & 106.4 & 13.0 & 42.5 & 8.41 \\
\hline & 75 & 107.4 & 5.60 & 44.3 & 6.07 \\
\hline & 150 & 96.6 & 3.14 & 51.4 & 2.33 \\
\hline \multirow{3}{*}{ EG } & 3 & 97.6 & 3.48 & 286.5 & 4.29 \\
\hline & 75 & 100.5 & 0.77 & 277.6 & 3.60 \\
\hline & 150 & 97.6 & 1.25 & 277.8 & 2.84 \\
\hline \multirow{3}{*}{ CG } & 30 & 96.0 & 1.36 & 113.8 & 6.64 \\
\hline & 75 & 96.6 & 6.01 & 121.9 & 3.24 \\
\hline & 150 & 96.5 & 6.89 & 126.7 & 2.02 \\
\hline
\end{tabular}

Table 4. Stability of anthraquinones in rat plasma $(n=3)$.

\begin{tabular}{|c|c|c|c|c|c|c|c|c|c|}
\hline \multirow[t]{2}{*}{ Analyte } & \multirow{2}{*}{$\begin{array}{c}\text { Conc. } \\
\text { (ng/mL) }\end{array}$} & \multicolumn{2}{|c|}{$\begin{array}{l}\text { Short Term } \\
\text { Stability (\%) }\end{array}$} & \multicolumn{2}{|c|}{$\begin{array}{c}\text { Long Term } \\
\text { Stability (\%) }\end{array}$} & \multicolumn{2}{|c|}{$\begin{array}{l}\text { Freeze and Thaw } \\
\text { Stability }(\%)\end{array}$} & \multicolumn{2}{|c|}{$\begin{array}{c}\text { Processed Sample } \\
\text { Stability (\%) }\end{array}$} \\
\hline & & Accuracy & RSD & Accuracy & RSD & Accuracy & RSD & Accuracy & RSD \\
\hline \multirow{3}{*}{$\mathrm{P}$} & 60 & 104.9 & 2.05 & 107.3 & 5.31 & 103.6 & 8.18 & 102.2 & 9.10 \\
\hline & 150 & 98.9 & 5.64 & 100.1 & 2.34 & 103.9 & 4.48 & 101.6 & 2.87 \\
\hline & 300 & 103.8 & 2.39 & 98.0 & 2.00 & 104.2 & 3.21 & 102.7 & 5.76 \\
\hline \multirow{3}{*}{ E } & 3 & 103.2 & 3.46 & 106.8 & 4.25 & 107.5 & 2.38 & 108.2 & 5.26 \\
\hline & 150 & 100.7 & 2.55 & 107.8 & 1.87 & 104.5 & 4.32 & 108.0 & 5.96 \\
\hline & 300 & 101.8 & 2.44 & 107.7 & 0.93 & 102.0 & 3.47 & 104.6 & 3.60 \\
\hline \multirow{3}{*}{ C } & 60 & 103.5 & 6.23 & 104.3 & 8.67 & 89.7 & 0.76 & 101.5 & 9.60 \\
\hline & 150 & 98.6 & 1.07 & 97.9 & 7.67 & 91.8 & 3.94 & 103.7 & 5.43 \\
\hline & 300 & 101.2 & 2.97 & 102.6 & 2.98 & 92.4 & 8.25 & 102.3 & 6.47 \\
\hline \multirow{3}{*}{ PG } & 30 & 98.9 & 9.48 & 97.7 & 5.64 & 101.5 & 9.06 & 98.8 & 6.33 \\
\hline & 75 & 91.8 & 6.60 & 98.5 & 5.36 & 94.3 & 6.57 & 92.7 & 4.64 \\
\hline & 150 & 96.7 & 1.62 & 97.1 & 2.85 & 93.6 & 2.16 & 96.8 & 1.19 \\
\hline \multirow{3}{*}{ EG } & 3 & 99.8 & 5.11 & 102.9 & 4.02 & 100.4 & 6.39 & 91.5 & 3.11 \\
\hline & 75 & 108.5 & 2.79 & 107.9 & 1.54 & 112.3 & 3.60 & 107.9 & 2.88 \\
\hline & 150 & 98.9 & 1.81 & 102.8 & 2.14 & 100.9 & 1.69 & 100.3 & 4.14 \\
\hline \multirow{3}{*}{ CG } & 30 & 97.6 & 9.29 & 97.5 & 4.04 & 98.3 & 4.81 & 91.1 & 2.45 \\
\hline & 75 & 96.9 & 0.56 & 100.6 & 1.38 & 101.0 & 2.23 & 100.2 & 7.38 \\
\hline & 150 & 101.8 & 5.27 & 101.5 & 2.52 & 97.0 & 5.66 & 96.7 & 5.93 \\
\hline
\end{tabular}

\subsection{Pharmacokinetics Study}

The validated LC-MS/MS method was applied to the pharmacokinetic study after oral administration of $R$. acetosa extract at a dose of $2 \mathrm{~g} / \mathrm{kg}$ to the rats. The concentrations of EG and $\mathrm{P}$ were not high enough to determine the pharmacokinetic parameters. The concentrations of $\mathrm{C}$ and PG were below the LLOQ from $6 \mathrm{~h}$ after administration of extract, CG and E could 
be detected until 8 and $24 \mathrm{~h}$, respectively. The mean plasma concentration-time profiles of the analytes are presented in Figure 4. The major pharmacokinetic parameters of C, E, CG, and PG calculated by non-compartmental analysis are listed in Table 5 . The data were expressed as mean \pm standard deviation. The concentrations of emodin fluctuated and were insufficient to calculate the half-life of elimination $\left(t_{1 / 2}\right)$. Meanwhile, rapid absorption of aglycones was observed because of the higher lipophilic character with $\mathrm{T}_{\max }$ of $0.25(0.25-0.5) \mathrm{h}$ and $0.25(0.25-0.75) \mathrm{h}$, compared with that of glycosides.

Table 5. The pharmacokinetic parameters of anthraquinones after oral administration of $R$. acetosa extract to rats at a dose of $2 \mathrm{~g} / \mathrm{kg}(n=3)$.

\begin{tabular}{cccccc}
\hline Analyte & $\left.\mathbf{A U C}_{\mathbf{0 - l a s t}^{\mathbf{a}}} \mathbf{( n g} \mathbf{h} / \mathbf{m L}\right)$ & $\mathbf{C}_{\max }(\mathbf{n g} / \mathbf{m L})$ & $\mathbf{T}_{\max } \mathbf{b}^{(\mathbf{h})}$ & MRT (h) & $\mathbf{t}_{\mathbf{1 / 2}}(\mathbf{h})$ \\
\hline C & $265.6 \pm 70.9$ & $155.6 \pm 86.0$ & $0.25(0.25-0.5)$ & $2.4 \pm 0.2$ & $3.9 \pm 0.6$ \\
E & $1165 \pm 336.1$ & $123.5 \pm 41.7$ & $0.25(0.25-0.75)$ & $7.7 \pm 3.0$ & NA \\
CG & $158.0 \pm 12.3$ & $28.7 \pm 4.7$ & $2(0.75-2)$ & $2.4 \pm 0.08$ & $4.8 \pm 0.5$ \\
PG & $82.8 \pm 13.8$ & $20.5 \pm 1.4$ & $0.75(0.5-2)$ & $2.7 \pm 0.6$ & $6.2 \pm 3.9$ \\
\hline
\end{tabular}

The values were expressed as mean \pm standard deviation except $\mathrm{T}_{\max }{ }^{\mathrm{a}}$ The last measured time points for $\mathrm{C}, \mathrm{E}, \mathrm{CG}$, and PG were 6, 24, 8, and $6 \mathrm{~h}$. ${ }^{\mathrm{b}}$ Median (range). $\mathrm{AUC}_{0-\text { last }}$, total area under the plasma concentration-time curve from time zero to last measured time; $C_{\max }$, maximum plasma concentration; $T_{\max }$, time to reach $\mathrm{C}_{\max } ; \mathrm{MRT}$, mean residence time; $\mathrm{t}_{1 / 2}$, half-life; NA, not available.
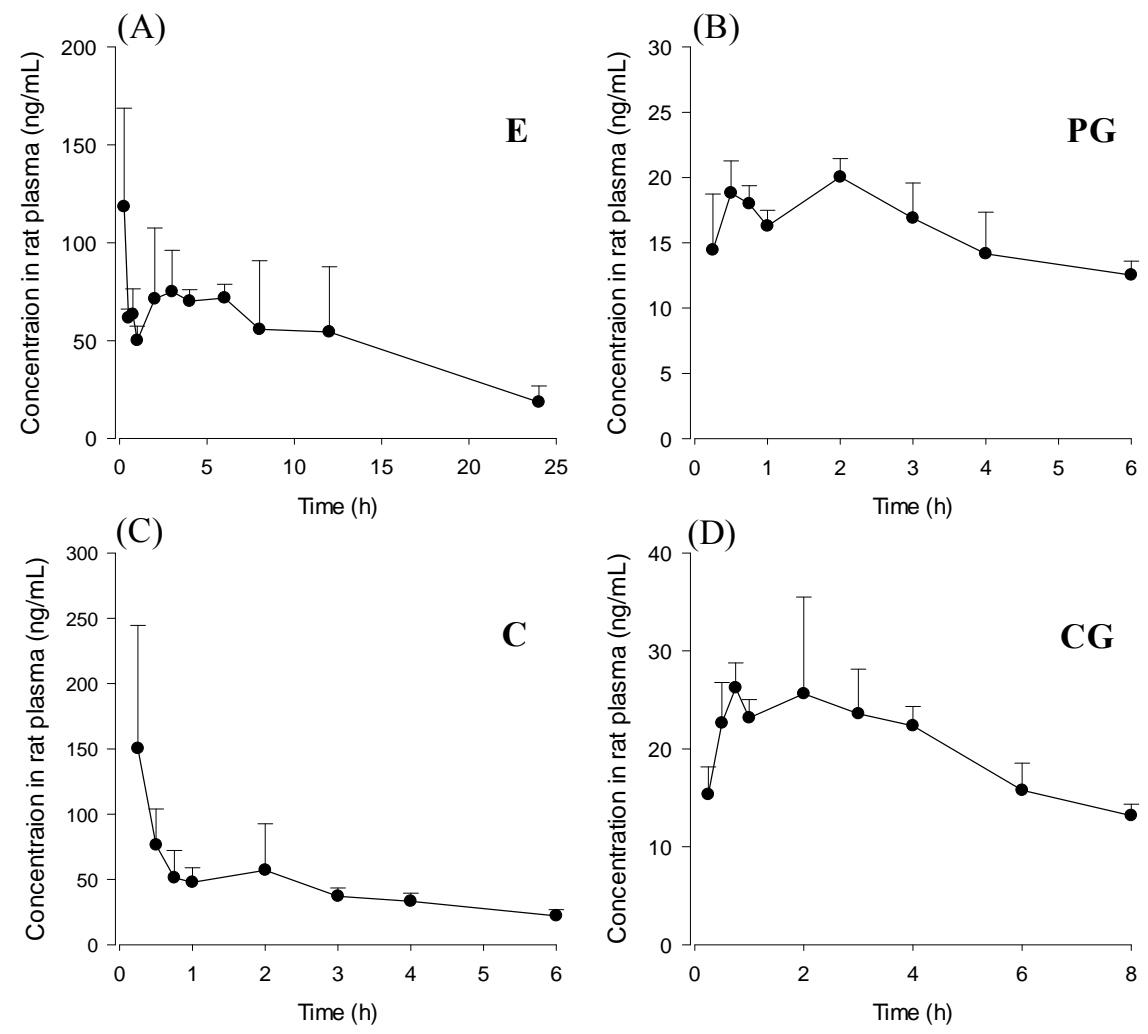

Figure 4. Mean plasma concentration-time profiles after oral $(n=3)$ administration of $R$. acetosa extract $(2 \mathrm{~g} / \mathrm{kg})$ to SD male rats. Bars represent standard deviation. (A) emodin; (B) physcion-8-O$\beta$-D-glucoside; (C) chrysophanol; (D) chrysophanol-8-O- $\beta$-D-glucoside.

\section{Discussion}

The objective of this study was to develop a bioanalytical method that simultaneously quantified the bioactive glycosides and aglycones of anthraquinones. The developed LC-MS/MS method could quantify six anthraquinones simultaneously in rat plasma in an accurate, reproducible, and simple 
way. Reported bioanalytical methods which simultaneously determine both aglycones and glycosides of anthraquinones are rarely available. In this study, simultaneous determination achieved by using biphenyl column. The column could prolong retention time of hydrophilic glycosides compare to C18 column at the same mobile phase composition.

There was no interfering peak when the compound mixture was spiked to blank rat plasma. However, there were small peaks appeared near CG and PG peaks after oral administration of plant extract. It is suggested that those peaks came from the extract or the metabolites of components in the extract. It is known that emodin is extensively glucuronized after absorption [14] and the molecular weight of emodin glucuronide is same as PG. There is some possibility that emodin glucuronide could interfere PG. However, the MS/MS fragment pattern of emodin glucuronide is different from PG. Emodin glucuronide might cause little interference. We could quantify CG and PG by adjusting the baselines because the interfering peaks were small.

A simple and rapid sample preparation was utilized on a low volume of rat plasma sample $(20 \mu \mathrm{L})$ by using methanol as a precipitating agent with appropriate sensitivity compare to the reported methods $[8,12,15]$. The comparison with reported analytical methods for aglycones and glycosides of anthraquinones was shown in Table 6.

Table 6. Comparison with reported analytical methods for aglycones and glycosides of anthraquinone.

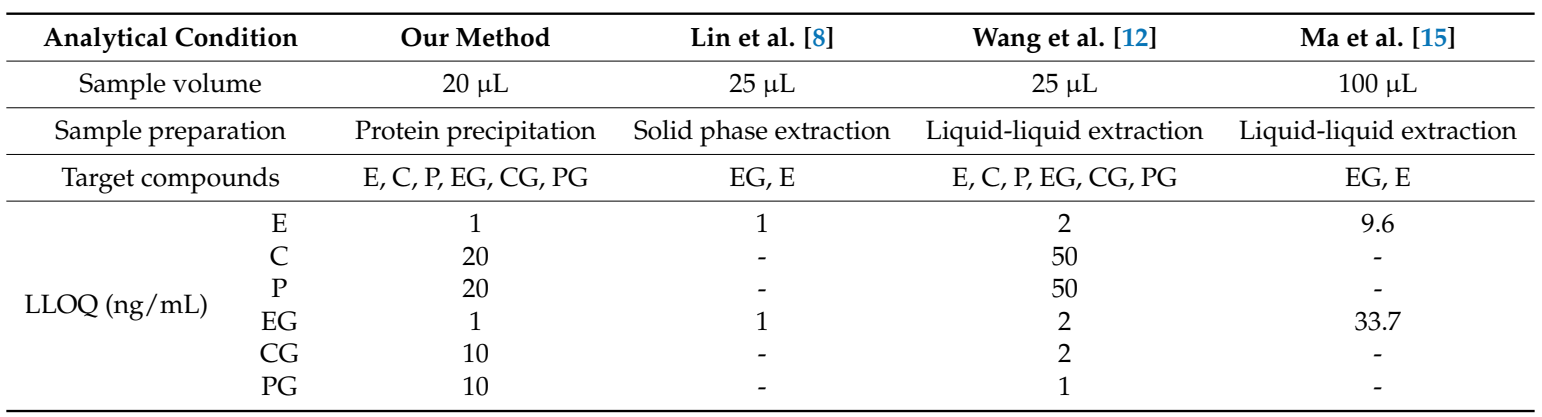

The method was acceptably validated and used to perform a pharmacokinetic study of anthraquinones after oral administration of $R$. acetosa in rats. As shown in Figure 4, C, E, CG, and PG could be detected in every rat from the first sampling time, $15 \mathrm{~min}$. All of the studied anthraquinones were absorbed rapidly from rat gastrointestinal tract. Median $\mathrm{T}_{\max }$ value of $\mathrm{C}$ and $\mathrm{E}$ was 15 min (Table 5). This result was consistent with reported values [8,10]. Emodin could be detected for the longest time among four compounds even though the concentrations fluctuated. The fluctuated concentration was also reported in other pharmacokinetic studies of emodin in rats [9,15]. This was possibly due to enterohepatic circulation [16]. In some other works [17], emodin rapidly and extensively metabolized to form its glucuronide and the parent form was almost undetectable after administration of emodin even the doses were similar $(40 \mathrm{mg} / \mathrm{kg}$ ) to our study $(18.8 \mathrm{mg} / \mathrm{kg}$ for $\mathrm{E}$ and $25.8 \mathrm{mg} / \mathrm{kg}$ for EG). Free emodin could be measured until $24 \mathrm{~h}$ after oral administration because of the low LLOQ level of emodin using the method developed in this work.

Generally, plant glycosides have been considered to be hydrolyzed to aglycones by microflora in the gastrointestinal tract before absorption [18]. Glycosides have large molecular weights and low lipophilicity, so they might be difficult to be absorbed. However, recent studies show that emodin glycoside can be absorbed in an intact form after oral administration of plant extract [8]. The absorption of the glycosides of anthraquinones in an intact form was confirmed by studying in vivo absorption in rats in this study. Pharmacokinetics of anthraquinone aglycones and their glycosides after oral administration of $R$. acetosa was first evaluated. CG and PG were detected in rat plasma after oral administration of $R$. acetosa extract. Interestingly, the $T_{\max }$ of $C$ and that of $C G$ were different after oral administration of the extract. It might be due to different lipophilicity. Glycosides and aglycones have been proposed to have different degrees of absorption and metabolic patterns. Note that second peaks 
in the plasma concentrations of aglycones were observed. This could be due to delayed absorption of aglycones hydrolyzed from glycosides by microflora in the gastrointestinal tract and enterohepatic circulation of anthraquinones [16]. A number of published studies have reported pharmacokinetics of anthraquinones. However, we found that most of these studies focused on determining aglycones. Pharmacokinetics of anthraquinone glycosides is rarely available. Wang et al. [12] recently reported the pharmacokinetics of anthraquinone aglycones and their glycosides in hyperlipidemic hamsters after administration of rhubarb. The plasma concentration-time profile patterns of anthraquinones were similar to our study even though the composition (dose ratio of compounds) of rhubarb extract might be quite different from $R$. acetosa extract and physiological differences between rats and hamsters probably exist. $\mathrm{T}_{\max }$ values of glycosides were slightly longer than aglycones. Similar to our results, emodin glucoside was not detected even though emodin could be detected until $36 \mathrm{~h}$. It is suggested that emodin glycoside probably rapidly hydrolyzed to emodin and was poorly absorbed as an intact form in the gastrointestinal tract.

Our pharmacokinetic study has some limitations. The number of animals $(n=3)$ is not enough to achieve statistically significant pharmacokinetic parameters after administration of an herbal product. The pharmacokinetic parameters obtained in this study might $b$ not sufficient to represent the animal population. Nevertheless, this study showed the possibility that our bioanalytical method could be used in pharmacokinetic studies of $R$. acetosa extract. Another issue to consider is that $R$. acetosa extract contained a number of other compounds besides anthraquinones. Further studies with a large sample size and studies of the effects of other compounds on the pharmacokinetics of anthraquinones are needed for better understanding of the pharmacokinetics of anthraquinones.

\section{Conclusions}

A simple and sensitive LC-MS/MS method for the determination of the glycosides and aglycones of anthraquinones in rat plasma was developed. The method was acceptably validated and applied to a pharmacokinetic study of anthraquinones after oral administration of $R$. acetosa extract in rats. The absorption of the glycosides of anthraquinones in an intact form was confirmed in the pharmacokinetic study. The results of this study could be relevant to a better understanding of the pharmacokinetics and pharmacodynamics of anthraquinone glycosides and aglycones.

Author Contributions: Conceptualization, M.-J.A. and H.J.C.; Formal analysis, J.K.; Funding acquisition, M.-J.A. and H.J.C.; Investigation, H.M.A.U., J.K., N.U.R., and H.-J.K; Methodology, H.J.C.; Project administration, H.J.C.; Writing—original draft, H.M.A.U.; Writing—review and editing, J.K., M.J.A. and H.J.C.

Funding: This work was supported by the National Research Foundation of Korea (NRF) grant funded by the Korean government (MSIP; Ministry of Science, ICT \& Future Planning) [Project No. 2017R1C1B5017343] and the R\&D Program for Forest Science Technology (Project No. 2017036A00-1719-BA01) provided by Korea Forest Service (Korea Forestry Promotion Institute).

Conflicts of Interest: The authors declare no conflict of interest.

\begin{tabular}{ll}
\multicolumn{2}{l}{ Abbreviations } \\
LC-MS/MS & $\begin{array}{l}\text { liquid chromatography-tandem mass spectrometry } \\
\text { multiple reaction monitoring } \\
\text { MRM }\end{array}$ \\
E & emodin \\
EG & emodin-8-O- $\beta$-D-glucoside \\
C & chrysophanol \\
CG & chrysophanol-8-O- $\beta$-D-glucoside \\
P & physcion \\
PG & physcion-8-O- $\beta$-D-glucoside
\end{tabular}




\section{References}

1. Lee, N.-J.; Choi, J.-H.; Koo, B.-S.; Ryu, S.-Y.; Han, Y.-H.; Lee, S.-I.; Lee, D.-U. Antimutagenicity and cytotoxicity of the constituents from the aerial parts of Rumex acetosa. Biol. Pharm. Bull. 2005, 28, 2158-2161. [CrossRef] [PubMed]

2. Kucekova, Z.; Mlcek, J.; Humpolicek, P.; Rop, O.; Valasek, P.; Saha, P. Phenolic compounds from Allium schoenoprasum, Tragopogon pratensis and Rumex acetosa and their antiproliferative effects. Molecules 2011, 16, 9207-9217. [CrossRef] [PubMed]

3. Gescher, K.; Hensel, A.; Hafezi, W.; Derksen, A.; Kühn, J. Oligomeric proanthocyanidins from Rumex acetosa L. inhibit the attachment of herpes simplex virus type-1. Antivir. Res. 2011, 89, 9-18. [CrossRef] [PubMed]

4. $\quad$ Bae, J.-Y.; Lee, Y.S.; Han, S.Y.; Jeong, E.J.; Lee, M.K.; Kong, J.Y.; Lee, D.H.; Cho, K.J.; Lee, H.-S.; Ahn, M.-J. A comparison between water and ethanol extracts of Rumex acetosa for protective effects on gastric ulcers in mice. Biomol. Ther. 2012, 20, 425-430. [CrossRef] [PubMed]

5. Bicker, J.; Petereit, F.; Hensel, A. Proanthocyanidins and a phloroglucinol derivative from Rumex acetosa L. Fitoterapia 2009, 80, 483-495. [CrossRef] [PubMed]

6. Fairbairn, J.W.; Reigal, E. Chemotaxonomy of anthraquinones in Rumex. Phytochemistry 1972, 11, $263-268$. [CrossRef]

7. Uddin, Z.; Song, Y.H.; Curtis-Long, M.J.; Kim, J.Y.; Yuk, H.J.; Park, K.H. Potent bacterial neuraminidase inhibitors, anthraquinone glucosides from Polygonum cuspidatum and their inhibitory mechanism. J. Ethnopharmacol. 2016, 193, 283-292. [CrossRef] [PubMed]

8. Lin, L.; Ni, B.; Lin, H.; Cao, S.; Yang, C.; Zhao, Y.; Xue, D.; Ni, J. Simultaneous determination and pharmacokinetic study of P-hydroxybenzaldehyde, 2,3,5,4'-tetrahydroxystilbene-2-O- $\beta$-glucoside, emodin-8-O- $\beta$-D-glucopyranoside, and emodin in rat plasma by liquid chromatography tandem mass spectrometry after oral administration of Polygonum multiflorum. Anal. Methods 2015, 7, 244-252. [CrossRef]

9. Wu, W.; Yan, R.; Yao, M.; Zhan, Y.; Wang, Y. Pharmacokinetics of anthraquinones in rat plasma after oral administration of a rhubarb extract. Biomed. Chromatogr. 2014, 28, 564-572. [CrossRef] [PubMed]

10. Yan, D.; Ma, Y. Simultaneous quantification of five anthraquinones in rat plasma by high-performance liquid chromatography with fluorescence detection. Biomed. Chromatogr. 2007, 21, 502-507. [CrossRef] [PubMed]

11. Vasas, A.; Orbán-Gyapai, O.; Hohmann, J. The genus rumex: Review of traditional uses, phytochemistry and pharmacology. J. Ethnopharmacol. 2015, 175, 198-228. [CrossRef] [PubMed]

12. Wang, M.; Hu, G.; Tian, Y.; Zhang, Z.; Song, R. Influence of wine-processing on the pharmacokinetics of anthraquinone aglycones and glycosides from rhubarb in hyperlipidemic hamsters. RSC Adv. 2016, 6, 24871-24879. [CrossRef]

13. US Food and Drug Administration. Guidance for Industry: Bioanalytical Method Validation, Draft Guidance; US Food and Drug Administration: Silver Spring, MD, USA, 2013.

14. Dong, X.; Fu, J.; Yin, X.; Cao, S.; Li, X.; Lin, L.; Huyiligeqi; Ni, J. Emodin: A review of its pharmacology, toxicity and pharmacokinetics. Phytother. Res. 2016, 30, 1207-1218. [CrossRef] [PubMed]

15. Ma, J.; Zheng, L.; He, Y.S.; Li, H.J. Hepatotoxic assessment of Polygoni multiflori radix extract and toxicokinetic study of stilbene glucoside and anthraquinones in rats. J. Ethnopharmacol. 2015, 162, 61-68. [CrossRef] [PubMed]

16. Shia, C.S.; Tsai, S.Y.; Lin, J.C.; Li, M.L.; Ko, M.H.; Chao, P.-D.L.; Huang, Y.C.; Hou, Y.C. Steady-state pharmacokinetics and tissue distribution of anthraquinones of Rhei rhizoma in rats. J. Ethnopharmacol. 2011, 137, 1388-1394. [CrossRef] [PubMed]

17. Shia, C.S.; Hou, Y.C.; Tsai, S.Y.; Huieh, P.H.; Leu, Y.L.; Chao, P.D. Differences in pharmacokinetics and ex vivo antioxidant activity following intravenous and oral administrations of emodin to rats. J. Pharm. Sci. 2010, 99, 2185-2195. [CrossRef] [PubMed]

18. Moreau, J.P.; Moreau, S.; Skinner, S. Comparative physiological disposition of some anthraquinone glycosides and aglycones. Biopharm. Drug Dispos. 1985, 6, 325-334. [CrossRef] [PubMed]

(C) 2018 by the authors. Licensee MDPI, Basel, Switzerland. This article is an open access article distributed under the terms and conditions of the Creative Commons Attribution (CC BY) license (http:/ / creativecommons.org/licenses/by/4.0/). 